P-ISSN: 2541-6960; E-ISSN: 2549-8754

Yupa: Historical Studies Journal

Vol. 3 No. 1, 2019 (18-27)

http://jurnal.fkip.unmul.ac.id/index.php/yupa

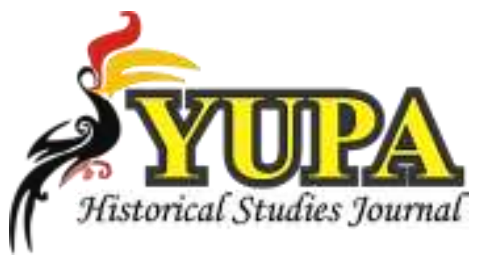

\title{
Pembelajaran Sejarah di Abad 21 (Telaah Teoritis terhadap Model dan Materi)
}

\author{
Een Syaputra1 $^{1}$ \& Sariyatun ${ }^{2}$ \\ 1'Institut Agama Islam Negeri Bengkulu, Bengkulu, Indonesia. \\ 2Universitas Sebelas Maret, Surakarta, Indonesia \\ 1eensyaputra23@gmail.com, 22sari_fkip_uns@yahoo.co.id
}

\begin{tabular}{ccc}
\hline Received & Accepted & Published \\
$07 / 06 / 2020$ & $25 / 06 / 2020$ & $30 / 06 / 2020$ \\
\hline
\end{tabular}

\begin{abstract}
Learning model and teaching material are two core elements that have problematic in 21st century. The purposes of this article is to conducted theoretical review of learning model and teaching material of history in the framework of 21st century education. This research was conducted with library research. The research steps undertaken are: 1) preparing tools and equipment; 2) compiling a working bibliography; 3) arranging research time; 4) reading and making research notes, and 5) concluding and analyzing the results of the research. The results of the review show that: 1) To develop 21st century skills in history learning, is needed learning model to connecting learning content of history with students live context, especially social problems in society. Furthermore, learning model in the framework of 21st century education are learning model that have the process of data collection and analysis, problem solving, and collaboration. Some models with the orientation skills are problem based learning, project based learning, discovery learning and inquiry learning; 2) To support 21st century skills, is needed the change of teaching material from text-based to web-based. For the content, teaching material based on problem and value are urgent to develop.
\end{abstract}

Keywords: Learning Model, Teaching Material, History Education, 21st Century Skills.

\begin{abstract}
Abstrak Model dan materi pembelajaran merupakan dua elemen inti yang masih mengalami banyak masalah dalam praksis pembelajaran Sejarah di abad 21. Artikel ini bertujuan untuk melakukan telaah teoritis terhadap model pembelajaran dan materi ajar Sejarah dalam bingkai pendidikan abad 21. Penelitian ini dilakukan dengan matode kepustakaan. Langkah penelitian yang dilakukan adalah: 1) menyiapkan alat dan perlengkapan; 2) menyusunn bibliografi kerja; 3) mengatur waktu penelitian; 4) membaca dan membuat catatan peneltian; dan 5) menyimpulkan dan menganalisis hasil peneltian. Hasil telaah menunjukkan bahwa: 1) Untuk mengembangkan keterampilan abad 21 dalam pembelajaran Sejarah, diperlukan model pembelajaran yang dapat menghubungkan materi pembelajaran Sejarah dengan kehidupan nyata peserta didik, terutama terhadap permasalahan sosial yang sedang terjadi di masyarakat. Selain itu, model pembelajaran dalam bingkai pendidikan abad 21 adalah model pembelajaran yang di dalamnya terdapat proses pengumpulan dan analsis data, pemecahan masalah, dan kolaborasi. Beberapa model yang memiliki orientasi ke arah keterampilan tersebut antara lain Problem Based Learning, Project Based Learning, Discovery Learnin, dan Inquiry Learning; 2) Untuk mendukung keterampilan abad 21, diperlukan perubahan dari materi yang bersifat text menjadi materi ajar yang berbasis website. Dari segi isi, materi ajar berbasis masalah sosial dan berbasis nilai, menjadi penting untuk dikembangkan.
\end{abstract}

Kata kunci: Model Pembelajaran, Materi Ajar, Pendidikan Sejarah, Keterampilan Abad 21. 


\section{PENDAHULUAN}

Cepatnya laju perkembangan ilmu pengetahuan, teknologi, infomasi, dan komunikasi di abad 21 telah melahirkan berbagai tantangan baru dalam kehidupan manusia. Redecker dkk (2011:12) mengidentifikasi enam tantangan utama di abad 21, yakni: 1) integrasi multikultural untuk mengakomodasi perubahan demografi dan imigrasi; 2) mengurangi jumlah masyarakat yang putus sekolah; 3) memperkuat potensi setiap individu untuk mengembangkan ekonomi cerdas pengetahuan dan inovasi; 4) mempercepat transisi dari dunia pendidikan menuju dunia kerja; 5) memfasilitasi kembali kesempatan masuk ke dunia kerja untuk menghindari pengangguran yang berkepanjangan; 6) berfokus pada pengembangan kembali kemampuan permanen yang menjadikan seluruh warga negara terhadap keterampilan-keterampilan baru yang dibutuhkan dan dengan cepat merespon perubahan lingkungan dunia kerja.

Untuk bisa bertahan di tengah kompleksitas tantangan dan rumitnya kehidupan di abad 21, ada beberapa kopetensi kunci yang harus dimiliki oleh generasi abad 21. Wagner (2010) berpendapat bahwa ada tujuh kompetensi dan keterampilan yang penting untuk dikuasai di abad ke-21 ini, yakni: 1) pemikiran kritis dan pemecahan masalah; 2) kolaborasi dan kepemimpinan; 3) ketangkasan dan kemampuan beradaptasi; 4) inisiatip dan kewiraswastaan; 5) komunikasi lisan dan tulisan yang efektif; 6) mengakses dan menganalsis informasi; dan 7) keingintahuan dan imajinasi. Senada dengan itu, Trilling \& Hood (1999:8) mengidentifikasi tujuh keterampilan kunci di abad 21, yakni: 1) critical thinking and doing; 2) creativity; 3) collaboration; 4) crosscultural understanding; 5) communication; 6) computing; dan 6) career and learning selfreliance.

Dalam upaya untuk membekali generasi muda dengan berbagai keterampilan di atas, maka peran dari dunia pendidikan menjadi sangat penting. Pendidikan, melalui programprogram dan mata pelajaran yang ada harus pekah dan tanggap terhadap berbagai kompetensi kunci yang diperlukan. Dengan kata lain bahwa pendidikan harus mampu membekali para peserta didik dengan keterampilan abad 21. Sejarah merupakan salah satu mata pelajaran wajib di semua jenis dan jenjang pendidikan. Untuk jenjang SMA, pembelajaran sejarah memiliki tujuh tujan utama, yakni: 1) mengembangkan pendalaman tentang peristiwa sejarah yang terpilih baik lokal maupun nasional; 2) mengembangkan keamampuan berpikir kritis dan kreatif; 3) membangun kepedulian dan semangar kebangsaan; 4) mengembangkan rasa ingin tahu, inspirasi, dan aspirasi; 5) mengembangkan sikap kepahlawanan dan kepemimpinan; 6) mengembangkan kemampuan mencari, mengolah, mengemas informasi; dan 7) dan mengkomunikasikan (Hasan, 2012:49).

Berdasarkan uraian di atas, dapat diambil keismpulan bahwa pada hakekatnya pendidikan sejarah merupakan mata pelajaran yang memiliki orientasi ke arah keterampilan abad 21. Karena itu, secara teoritis dan filosofis dapat dikatakan bahwa pendidikan sejarah 
merupakan salah satu mata pelajaran yang memainkan peran penting dan strategis dalam mengembangkan keterampilan abad 21. Hal ini juga sebagaimana disebutkan oleh Partnership for 21st Century Learning bahwa sejarah merupakan satu diantara sembilan mata pelajaran kunci dalam pembelajaran abad 21 (P21, 2015:2).

Namun realita di lapangan menunjukkan hasil yang sebaliknya. Pembelajaran sejarah gagal dalam menumbuhkan nilai-nilai kemanusian kepada peserta didik. Pembelajaran sejarah juga gagal dalam menumbuhkan kesadaran sosial dan kompetensi lain yang dibutuhkan untuk mewujudkan kehidupan sosial yang harmoni (Syaputra, Sariyatun \& Sunardi, 2018). Tidak hanya itu, pembelajaran sejarah juga gagal dalam mewujudkan peserta didik yang memiliki kemampuan berpikir kritis-analisis dan kreatif sebagai basis pemecahan masalah dan bekal dasar dalam menghadapi persaingan global (Supriatna, 2011; Syaputra \& Dewi, 2020). Singkatnya, pembelajaran sejarah di sekolah belum memberikan kontribusi yang memadai bagi pengambangan keterampilan abad 21 kepada peserta didik. Karena itu perlu dilakukan perubahan dalam pelaksanaan pembelajaran sejarah di sekolah, yakni dengan mengacu kepada paradigma pendidikan abad 21.

Model dan materi pembelajaran merupakan dua elemen penting dalam pembelajaran sejarah. Dalam hubungannya dengan keterampilan abad 21, maka model dan materi pembelajaran sejarah sjuga harus menyesuaikan dengan karakteristik pendidikan abad 21. Dengan kata lain bahwa model dan materi pembelajaran yang dipilih/dikembangkan harus sejalan dengan kompetensi yang diinginkan dikembangkan kepada peserta didik. Karena itu, artikel ini bertujuan untuk melakukan telaah literatur terkait dengan model dan materi pembelajaran sejarah dalam bingkai pendidikan abad 21.

\section{METODE}

Penelitian ini merupakan penelitian kepustakaan dengan pendekatan deskriptif analisis, yakni serangkaian kegiatan yang berkenaan dengan metode pengumpulan data pustaka, membaca serta mencatat dan mengola data penelitian (Zed, 2008:3). Karena itu, dalam penelitian ini, peneliti hanya membatasi diri bahan-bahan kepustakaan saja, terutama buku dan hasil-hasil penelitian terdahulu yang membahas tentang pendidikan dan keterampilan abad 21, model dan materi pembelajaran sejarah abad 21, dan lain-lain. Beberapa langkah yang dilakukan dalam penelitian ini adalah: 1) menyiapkan alat dan perlengkapan; 2) menyusunn bibliografi kerja; 3) mengatur waktu penelitian; 4) membaca dan membuat catatan peneltian; dan 5) menyimpulkan dan menganalisis hasil peneltian (Zed, 2008). 


\section{HASIL DAN PEMBAHASAN}

\section{Paradigma Pendidikan Abad 21}

Dalam upaya membekali peserta didik dengan berbagai keterampilan abd 21 sebagaimana dibahas di atas, maka dibutuhkan sebuah desain pendidikan yang juga sesuai dengan konteks yang ada (abad 21). Berkenaan dengan itut, Wagner dkk (2006) menekankan pada pentingnya pengembangan kurikulum dengan prinsif baru yang disebut dengan istilah The New 3 Rs (Rigor, Relevance, \& Respect). Rigor berarti bahwa pembelajaran yang dilaksanakan harus bersifat fleksibel, tidak kaku dan monoton. Relevance berarti bahwa pembelajaran yang dilaksanakan harus memperhatikan relevansinya dengan dunia nyata dan tuntutan dunia di masa depan. Adapun respect ialah prinsif yang berkenaan dengan hubungan interaksi antara guru dan siswa, yakni pola interaksi yang membina kompetensi akadmeik dan sosial.

Senada dengan pendapat di atas, Prensky (2012) menganjurkan untuk mengembangkan kurikulum yang berpusat pada siswa dengan komponen The 3 Ps. Ps yang pertama adalah passion, yang berarti bahwa pendidikan harus mampu melahirkan peserta didik yang memiliki keterampilan atau keahlian khusus. Ps yang kedua adalah problem solving, yang mengandung maksud bahwa kurikulum harus mengarahkan siswa untuk memiliki keterampilan dalam memecahkan masalah. Adapun Ps yang ketiga adalah producing what is required creativity and skill, yang berarti bahwa pendidikan harus mampu menghasilkan peserta didik yang memiliki keterampilan dan kreativitas yang sedang dibtuhkan oleh dunia kerja.

Selain beberapa pendapat di atas, Partnership for 21st Century Learning mengembangkan sebuah framework pembelajaran di abad 21 yang menuntut peserta didik untuk memiliki keterampilan, pengetahuan dan kemampuan dibidang teknologi, media dan informasi, keterampilan pembelajaran dan inovasi serta keterampilan hidup dan karir (P21, 2015). Framework ini juga menjelaskan tentang keterampilan, pengetahuan dan keahlian yang harus dikuasai agar siswa dapat sukses dalam kehidupan dan pekerjaannya. Framework tersebut dapat dilihat melalui gambar berikut ini. 


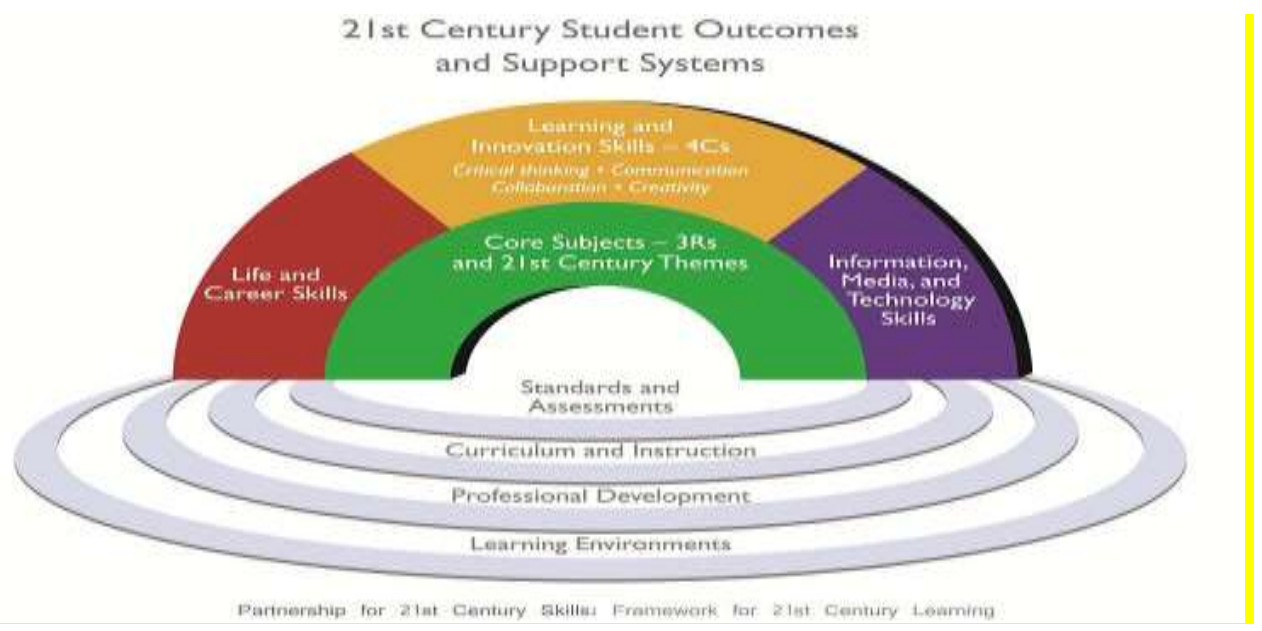

Sumber: P21. 2015. P21 Framework Definitions. HIm. 1

Berbagai prinsip di atas juga menuntut untuk dilakukan perubahan paradigma dalam pembelajaran di abad 21. Peruabhan paradigma tersebut setidaknya harus dilakukan terhadap empat hal. Pertama, terkait dengan informasi. Pada abad ke 21 ini, informasi bukanlah sesuatu yang sulit dicari, sehingga pembelajaran harus diarahkan agar peserta didik agar mencari tahu informasi dari berbagai macam sumber. Kedua, pembelajaran harus diarahkan agar peserta didik memiliki kemampuan merumuskan, mengidentifikasi dan menganalisis suatu permasalahan, bukan hanya sekedar menyelesiakan suatu masalah yang telah diidentifikasi apa permasalahannya. Ketiga, pembelajaran harus diarahkan untuk melatih kemampuan berpikir analitis (pengambilan keputusan) bukan berpikir mekanistis (rutin) yang bersifat hapalan. Keempat, pembelajaran harus menekankan pada pentingnya kolaborasi dan kerjasama dalam menyelesaikan masalah. Hal ini penting mengingat semakin kompleksitasnya permasalahan yang dihadapi sehingga membutuhkan berbagai kemampuan khusus dari berbagai bidang dalam waktu yang bersamaan. Beberapa perubahan paradigma ini dapat di lihat pada tabel berikut ini:

\section{Tebel 1. Pergeseran Paraidigma Belajar Abad 21}

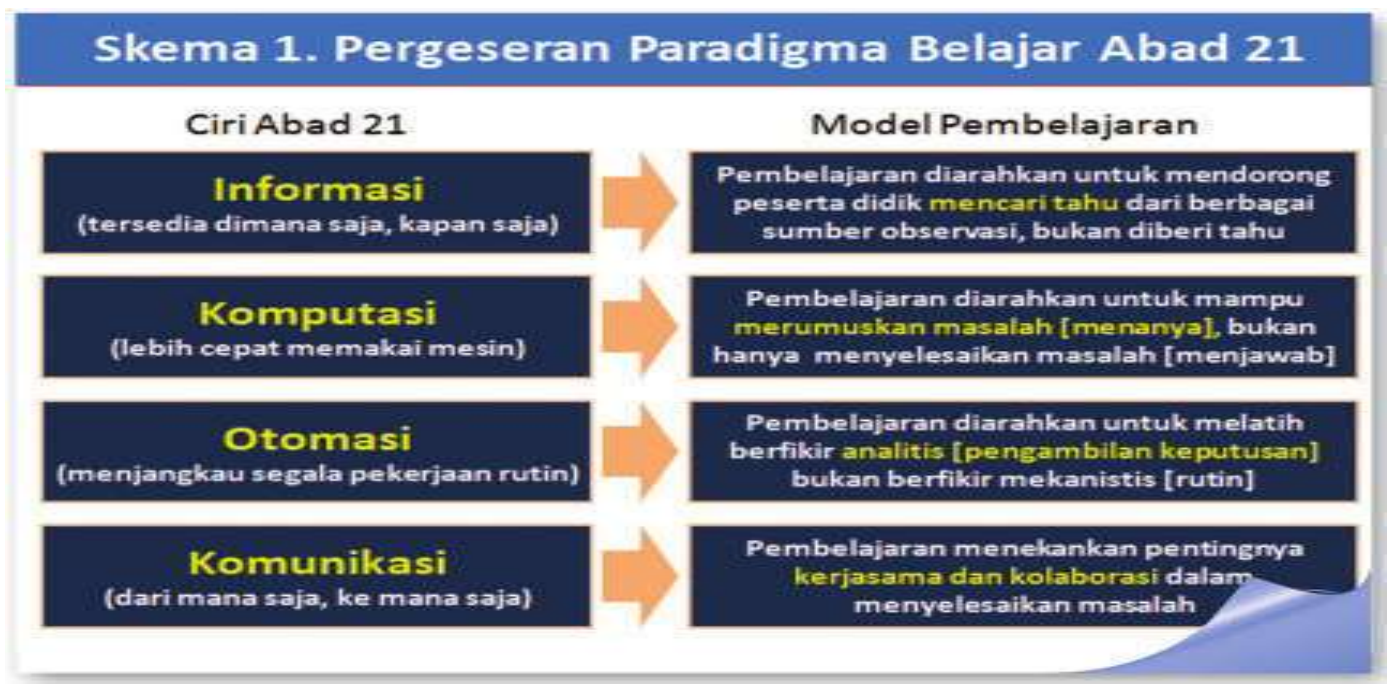


Selain beberapa perubahan di atas, Trilling \& Fadel (2009) dalam bukunya: $21^{\text {st }}$ Century Skills: Learning for Life in Our Times menjelaskan bahwa untuk dapat mengembangkan keterampilan abad 21 harus dilakukan perubahan dalam praktek pembelajaran dari TeacherDirected menuju Learner-Centered. Berikut ini adalah beberapa item hal yang harus dilakukan perubahan dalam pembelajaran di abad 21: 1) dari direct instruction menuju interactive exchange; 2) dari knowledge menuju skills; 3) dari berorientasi content menuju proses; 4) dari basic skills menuju applied skills; 5) dari facts and principles menuju questions and problems; 6) dari theory menuju practice; 7) dari berbasis kurikulum menuju pembelajaran berbasis projects; 8) dari time-slotted menuju on-demand; 9) dari one-size-fifits-all menuju personalized; 10) dari competitive menuju collaborative; 11) dari classroom menuju global community; 12) dari textbased menuju web-based; 13) dari summative tests menuju formative evaluations; dan 14) dari learning for schools menuju learning for life.

\section{Model Pembelajaran Sejarah Abad 21}

Model merupakan salah satu elemen penting dalam pembelajaran sejarah. Dalam memilih model pembelajaran, pertimbangan utama yang harus diperhatikan adalah tujuan pembelajaran yang ingin dicapai. Dalam hubungannya dengan keterampilan abad 21, maka model yang dipilih haruslah yang memiliki kesesuaian dengan keterampilan abad 21, yakni model pembelajaran yang dapat mengembangkan kemampuan berpikir kritis dan pemecahan masalah, melatih kreativitas, membangun kolaborasi dan kepemimpinan serta melatih kemampuan dalam berkomunikasi. Tabel berikut akan menyajikan beberapa model pembelajaran yang memiliki orientasi ke arah pengembangan keterampilan abad 21:

Tabel 2. rekap Model Pembelajaran Sejarah Abad 21

\begin{tabular}{|c|l|l|}
\hline No & Model Pembelajaran & Deskripsi/Keterangan Relevansi \\
\hline 1 & Problem Based & $\begin{array}{l}\text { Melalui PBL, siswa akan diberikan sebuah masalah secara tidak } \\
\text { terstuktur tentang suatu permasalahan tertentu yang ada dalam } \\
\text { kehidupan nyata untuk kemudian dicarikan solusinya melalui } \\
\text { (Jungyoun, 2018). Dalam PBL siswa secara bersama-sama akan } \\
\text { belajar menyusun strategi, mengumpulkan informasi, hingga } \\
\text { akhirnya memberikan rekomendasi solusi (Grant \& Branch, 2005). } \\
\text { Relevansi utama dari PBL keterampilan berpikir ktritis dan } \\
\text { pemecahan masalah. Selain itu, PBL juga dapat secara aktif } \\
\text { mengembangkan keterampilan berkomunikasi, kreativitas, serta } \\
\text { kolaborasi (Huang, 2018). }\end{array}$ \\
\hline $\mathbf{2}$ & $\begin{array}{l}\text { Project Based } \\
\text { Learning }\end{array}$ & $\begin{array}{l}\text { Melalui Project Based Learning peserta didik akan memecahkan } \\
\text { masalah dunia nyata dengan merancang pertanyaan mereka } \\
\text { sendiri, merencanakan pembelajaran, mengatur penelitian dan } \\
\text { menerapkan berbagai strategi yang dibutuhkan. Model ini memiliki } \\
\text { orientasi ke arah pemecahan masalah, berpikir kritis, dan berpikir } \\
\text { kreatif. Selain itu model ini, juga dapat membantu siswa dalam } \\
\text { mengembangkan kemampuan kolaborasi dan komunikasi (Bell, } \\
\text { 2010; Boonde, Kidrakarn, \& Ngiamvibool, 2011). }\end{array}$ \\
\hline $\mathbf{3}$ & Inquiry Learning & $\begin{array}{l}\text { Inquiri adalah model dimana siswa diminta untuk dapat mencari } \\
\text { dan menemukan jawaban atas suatu persoalan melalui metode }\end{array}$ \\
\hline
\end{tabular}




\begin{tabular}{|c|l|l|}
\hline & & $\begin{array}{l}\text { ilmiah. Model ini sangat membantu siswa dalam mengembangkan } \\
\text { kemampuan berpikir kritis dan pemecahan masalah (Price \& } \\
\text { Driscoll, 1997; Duran \& Dokme, 2016). }\end{array}$ \\
\hline 4 & Discovery Learning & $\begin{array}{l}\text { Model discovery merupakan model pembelajaran yang } \\
\text { dikembangkan atas dasar pendekatan konstruktivis (Balim, 2009). } \\
\text { Dalam discovery learning siswa membangun pengetahuan } \\
\text { berdasarkan informasi dan data baru yang dikumpulkan (Saab dkk, } \\
\text { 2005). Model discovey adalah model yang tepat untuk } \\
\text { mengembangkan kemampuan menemukan gagasan, berpikir kritis, } \\
\text { bertanya, serta keterampilan memecahkan masalah. }\end{array}$ \\
\hline
\end{tabular}

Sumber: Hasil Analisis Peneliti.

Secara teoritis, keempat model di atas memimiliki keunggulan dalam mengembangkan keterampilan abad 21 karena secara aktif melibatkan siswa dalam proses pengumpulan data dan analisis data, pemecahan masalah, serta kerjasma dalam dalam kelompok. Pengumpulan data, analisis data, dan penyelesaian masalah merupakan hal yang dibutuhkan untuk mengambangkan kemampuan berpikir kritis dan problem solving, melatih kreatifitas serta membantu siswa dalam menemukan pengetahuan baru. Adapun kerjasama dalam kelompok merupakan kegiatan yang dibutuhkan untuk mengembangkan kemampuan manajemen kerja, kolaborasi, sikap saling menghargai serta keterampilan dalam berkomunikasi.

\section{Materi Pembelajaran Sejarah Abad 21}

Selain model, materi pembelajaran juga merupakan salah satu elemen penting dalam pendidikan sejarah. Secara teoritis, materi pembelajaran sejarah harus dapat menunjang tercapainya tujuan pendidikan sejarah, yakni terwujudnya peserta didik yang mampu mengambil keputusan dan melahirkan tindakan-tindakan yang rasional dalam menghadapi permasalahan yang ada di masyarakat. Materi pembelajaran sejarah juga harus dapat memfasilitasi peserta didik untuk mengembangkan kemampuan berpikir kritis, kreatif, serta mengembangkan nilainilai dasar dalam kehidupan bermasyarakat, berbangsa dan bernegara. Dalam hubungannya dengan keterampilan abad 21, materi pembelajaran sejarah harus dapat mengembangkan keterampilan berpikir kritis dan pemecahan masalah, mengembangkan kreativitas, keterampilan berkomunikasi, dan kemampuan dalam berkolaborasi.

Berdasarkan hasil analisis, berikut ini merupakan beberapa bentuk/jenis materi pembelajaran yang perlu dihadirkan/dikembangkan untuk mengembangkan keterampilan abad 21 dalam pembelajaran sejarah:

Tabel 3. Rekap Materi Pembelajaran Sejarah Abad 21

\begin{tabular}{|l|l|l|}
\hline No & Item & Deskripsi \\
\hline 1 & Bentuk Materi & $\begin{array}{l}\text { Materi berbasis website, yang bisa diakses secara online. Bentuknya } \\
\text { antara lain seperti: e-book, e-archive, e-journal, atau dalam bentuk lain } \\
\text { seperti media sosial, majalah dan lain sebagainya yang memuat } \\
\text { informasi tentang topik yang dipelajari. }\end{array}$ \\
\hline
\end{tabular}




\begin{tabular}{|l|l|l|}
\hline 2 & Isi Materi & $\begin{array}{l}\text { Materi berbasis permasalahan dan isu-isu sosial, terutama masalah } \\
\text { sosial kontemporer seperti keruskaan lingkungan, bencana alam, } \\
\text { wabah, kemiskinan, dll. Dalam konteks sejarah, bisa juga berupa } \\
\text { peristiwa sejarah yang kontroversial. }\end{array}$ \\
& $\begin{array}{l}\text { Materi berbasis nilai atau materi yang kaya akan muatan nilai. Dalam } \\
\text { sejarah, materi berbasis nilai dapat bersumber dari pemikiran dan } \\
\text { teladan tokoh, kearifan lokal, peristiwa sejarah, dan lain-lain. }\end{array}$ \\
\hline
\end{tabular}

\section{Sumber: Hasil Analisis Peneliti.}

Dari tabel di atas, dapat dipahami bahwa secara umum terdapat dua hal penting yang berkaitan dengan materi pembelajaran sejarah abad 21. Pertama, terkait dengan bentuk materi. Untuk dapat mengembangkan keterampilan abad 21, materi pembelajaran harus berubah dari yang sebelumnya hanya berbasis teks (text-based) menjadi materi pembelajaran yang berbasis non teks atau berbasis (web-based). Dengan demikiam, maka materi pembelajaran yang biasanya hanya didapatkan melalui buku teks atau LKS, perlahan harus berganti kepada materi pembelajaran yang tersedia dalam bentuk digital, baik berupa e-book, e-journal, e-archive, majalah, media sosial, dan lain-lain yang bisa diakses kapan saja dan dimana saja. Hal ini sejalan dengan karakteristik abad 21, dimana kemajuan teknologi, informasi dan komunikasi terjadi dengan sangat cepat.

Kedua, isi materi pembelajaran, dimana diperlukan materi pembelajaran sejarah yang berbasis masalah-masalah sosial kekinian (kontemporer) dan materi pembelajaran berbasis nilai. Materi berbasis permasalahan sosial atau isu-isu sosial merupakan materi yang sangat diperlukan dalam proses pengembangan kemampuan berpikir kritis dan pemecahan masalah. Selain itu, materi pembelajaran berbasis masalah-masalah sosial juga diperlukan untuk menghubungkan materi pembelajaran sejarah sebagai peristiwa masa lalu dengan kehidupan kekinian peserta didik. Hal ini sejalan dengan kritik Supriatna (2011) yang menjelaskan bahwa pembelajaran sejarah selama ini menjadi kurang bermakna karena materi pembelajaran terlepas dari konteks sosial peserta didik sehingga tidak mampu menjadi penghubung antara dunia pengetahuan dengan dunia realitas.

Adapun materi berbasis nilai, keberadaannya sangat diperlukan sebagai bagian dari upaya mendukung proses penanaman nilai dan pembentukan karakter, terutama nilai-nilai yang berhubungan dengan kehidupan sosial kebangsaan (yang mendukung terwujudnya good citizen). Selain itu, materi pembelajaran berbasis nilai juga diperlukan sebagai solusi terhadap materi pembelajaran sejarah yang selama ini dianggap hanya sekedar tentang fakta-fakta (nama orang/tokoh, tanggal dan tahun kejadian, nama peristiwa, dan lain-lain). Hal ini juga sejalan dengan kritik Hasan (2012) yang mengatakan bahwa materi pembelajaran yang diajarkan di sekolah cenderung menjadi materi tentang fakta-fakta namun kering akan nilai-nilai. Terkhsus untuk materi pembelajaran berbasis nilai kearifan lokal, keberadaannya sangat diperlukan dalam upaya pembentukan identitas peserta didik agar tidak terputus dari realitas budayanya 
(Sariyatun, 2011). Selain itu, pemanfaatan kearifan lokal sebagai bahan ajar pendidikan sejarah dapat pula menjadi bagian dari usaha untuk memasukkan peran dari ordinary people dan pengalaman sosial sebagai small narrative (narasi penggiran) yang selama ini menjadi korban dari hegemonic group (Supriatna, 2011).

\section{KESIMPULAN}

Dalam rangka mengembangkan keterampilan abad 21, diperlukan model pembelajaran sejarah yang secara aktif melibatkan peserta didik dalam proses pengumpulan data dan analisis data, pemecahan masalah, serta kerjasma dalam dalam kelompok. Beberapa diantara model dengan karakteristik tersebut adalah problem based learning (PBL), project based learning, discovery learning, dan inquiry learning. Untuk materi pembelajaran, pembelajaran sejarah abad 21 membutuhkan materi ajar berbasis masalah sosial kekinian yang sedang dihadapi oleh peserta didik. Selain itu, materi pembelajaran sejarah haruslah materi yang kaya akan muatan nilai-nilai, terutama nilai-nilai lokal seperti kearifan lokal. Dari segi bentuk materi ajar, dibutuhkan materi ajar yang tidak hanya berbasis teks, namun juga materi ajar berbasis website sehingga memungkinkan bagi siswa untuk mengakses berbagai macam dan bentuk informasi yang dibutuhkan.

\section{REFERENSI}

Balim, A. G. (2009). The Effects of Discovery Learning on Students' Success and Inquiry Learning Skills. Eurasian Journal of Educational Research, 35: 1-20.

Bell, S. (2010). Project-Based Learning for the $21^{\text {st }}$ Century: Skills fot the Future. The Clearing House, 83 (2): 39-43.

Boondee, V., Kidrakarn, P., \& Ngiamvibool, W. (2011). A Learning and Teaching Model Using Project-Based Learning (PBL) on the Web to Promote Cooperative Learning. European Journal of Social Sciences, 21 (3): 498-506.

Duran, M., \& Dokme, I. (2016). The Effect of the Inquiry-Based Approach on Students Critical Thinking Skills. Eurasia Journal of Mathematics, Science \& Technology Education, 12 (12): 2887-2908.

Grand, M. M., \& Branch, R. M. (2005). Project Based Learning in a Middle School: Tracing Abilities through the Artifacts of Learning. Journal of Research on Technology in Education, 38 (1): 65-98.

Hasan, S.H. (2012). Pendidikan Sejarah Untuk Memperkuat Pendidikan Karakter. PARAMITA: Jurnal Sejarah dan Pembelajaran Sejarah, 22 (1) 81-95.

Hasan, S. H. 2012. Pendidikan Sejarah Indonesia: Isu dalam Ide dan Pembelajaran. Bandung: Rizqi Press.

Huang, R. (2005). Chinese International Students' Perceptions of the Problem Based Learning. Journal of Hospitality, Leisure, Sport and Tourism Education, 4 (2): 36-43. 
Jungyoun, H. (2018). A Study on Development and Effectiveness of a Teaching-Learning Model Based on Flipped Learning and PBL. Journal of Problem Based Learning, 5 (1): 45-54.

Prensky, M. (2012). From Digital Natives to Digital Wisdom: Hopeful Essays for 21st Century Learning. Thousand Oaks, CA: Corwin Press.

Prise, E. A., \& Driscoll, M. P. (1997). An Inquiry Into the Spontaneous Transfer of Problem Solving Skills. Contemporary Educational Psychology, 22: 497-494.

P21. (2015). P21 Framwork Definitions. Washington DC: Partnership for 21st Century Skills.

Redecker, C et al dkk. (2011). The Future of Learning: Preparing for Change. Luxembourg: Publications Office of the European Union.

Saab, M., Joonlingen, W. R., \& Wolters, B. H. A. M. (2005). Communication in Collaborative Discovery Learning. British Journal of Educational Psychology, 75: 603-621.

Sariyatun. (2011). Pengembangan Model Pendidikan Nilai-Nilai Budaya di SMP Berbasis Tradisi Seni Batik Klasik di Surakarta. PARAMITA: Historical Studies Journal, 23 (2): 230-241.

Supriatna, N. (2011). Konstruksi Pembelajaran Sejarah Berorientasi pada Permasalahan Sosial Kontemporer. Mimbar Pendidikan: Jurnal Indonesia untuk Kajian Pendidikan, 27 (1) 2130 .

Syaputra, E., \& Dewi, D. E. C. (2020). Tradisi Lisan sebagai Bahan Pengembangan Materi Ajar Pendidikan IPS di SMP: Sebuah Telaah Literatur. Jurnal Teori dan Praksis Pembelajaran IPS, 5 (1): 51-62.

Syaputra, E., Sariyatun, S., \& Sunardi, S. (2018). The Strategy of Enhancing Student's Social Awareness through History Learning Based on Selimbur Caye Oral Tradition Values. International Journal of Multicultural and Multireligious Understanding, 5 (4): 22-29.

Trilling, B., \& Hood, P. (1999). Learning, Technology and Education Reform in the Knowledge Age. Educational and Technology, 39 (3): 5-18.

Trilling, B., \& Fadel, C. (2009). 21st Century Skills: Learning for Life in Our Time. San Francisco: Jossey-Bass.

Wagner, T. (2010). The Global Acheivement Gap: Why Even Our Best Schools Don't Teach the New Survival Skills Our Children Need and What We Can Do About It. New York: Basic Books.

Zed, M. (2008). Metode Kepustakaan. Jakarta: Obor. 